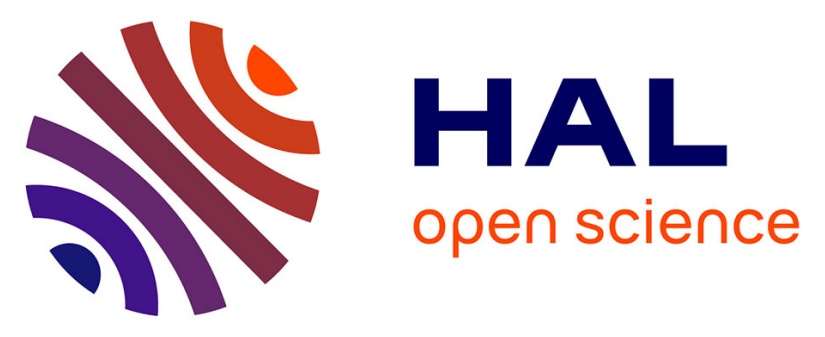

\title{
Business Modeling Toward Competitiveness and Ciborra's Criticism: Results from an IT-Business Strategic Alignment via an Action-Research
}

Nemer Alberto Zaguir, Mauro De Mesquita Spinola, Fernando Laurindo

\section{To cite this version:}

Nemer Alberto Zaguir, Mauro De Mesquita Spinola, Fernando Laurindo. Business Modeling Toward Competitiveness and Ciborra's Criticism: Results from an IT-Business Strategic Alignment via an Action-Research. IFIP International Conference on Advances in Production Management Systems (APMS), Sep 2016, Iguassu Falls, Brazil. pp.239-247, 10.1007/978-3-319-51133-7_29 . hal-01615731

\author{
HAL Id: hal-01615731 \\ https://hal.inria.fr/hal-01615731
}

Submitted on 12 Oct 2017

HAL is a multi-disciplinary open access archive for the deposit and dissemination of scientific research documents, whether they are published or not. The documents may come from teaching and research institutions in France or abroad, or from public or private research centers.
L'archive ouverte pluridisciplinaire HAL, est destinée au dépôt et à la diffusion de documents scientifiques de niveau recherche, publiés ou non, émanant des établissements d'enseignement et de recherche français ou étrangers, des laboratoires publics ou privés. 


\title{
Business Modeling Toward Competitiveness and Ciborra's Criticism: Results from an IT-Business Strategic Alignment via an Action-Research
}

\author{
Nemer Alberto Zaguir ${ }^{1, *}$, Mauro de Mesquita Spinola ${ }^{1}$, and Fernando José \\ Barbin Laurindo ${ }^{1}$ \\ ${ }^{1}$ University of São Paulo, SP, Brazil \\ *nemer .zaguir@gmail.com
}

\begin{abstract}
The IT-business strategic alignment (ITBSA) aims to promote greater IT effectiveness by making it active in the firms' competitiveness agenda. Despite the relevance of the theme, ITBSA is not free from criticism. Ciborra criticized how ITBSA research programs have been developed and its sufficiency for an effective strategic planning. This article shows how a business model in a small real estate firm was deployed for revenue generation through an Action-Research (AR) conducted to evaluate Ciborras' criticism. The results show ITBSA critics from the field and a new business model direction. The ITBSA was concluded to have structured the strategic discussion; however, Ciborra's inputs about the importance of bricolage, cyclical learning was conquered by an influence of the researcher as an agent of change applying AR under the critical theory paradigm. We suggest future research with more comprehensive literature review about our usual assumptions of economic rationality.
\end{abstract}

Keywords: Action Research · Business Modeling · Ciborra Competitiveness · IT-Business Strategic Alignment

\section{Introduction}

In recent years, the Brazilian real estate sector has experienced significant changes, whose reflections led companies to reassess their strategies, tactical actions and even their organizational structure [1]. For small and medium enterprises, abrupt changes in the external environment can pose threats that, if not properly managed, can compromise their performance, confirming the importance of competitiveness analysis. In this context, how can Information Technology (IT) contribute to the competitiveness of these companies?

The literature on IT-Business strategic alignment (ITBSA) confirms that technological excellence, the pursuit of operational efficiency, optimization of implementation processes and development systems do not guarantee the effectiveness of IT and its contribution to competitiveness, thus requiring an analysis of the strategic impact of IT on the organization. To accomplish this, ITBSA models could be applied. One such model is the MAN/TI-2 [2] which includes 
company's structural factors, IT organizational factors and the recommendation to confront the analysis of two groups promoting adjustments for IT to be effective.

Although the ITBSA promotes the IT strategic role, it is not exempt from criticism. Ciborra [3] questioned how the ITBSA was developed, noting it is not enough for alignment in practice. Ciborra [4] also questioned the strategic planning process involving IT, stating that, to satisfy the condition to gain competitive advantage, it should seek innovation, which suggests a plan designed with greater freedom of experimentation, learning posture with flaws and opportunities.

This research was motivated by the need of a small real estate company, which required a new business model based on a peculiar opportunity identified after the sale of some internal business processes as a service to a real estate partner. The transformation of this opportunity into a new business, promises to be a source of revenue and competitive advantage empowered by IT. In order to address this issue, it was performed an ITBSA project to design and deploy this new business model, denominated "Business Process Outsourcing" (BPO).

This research aimed to assess four Ciborra's criticism during the ITBSA project. For this, the ITBSA project applied models from MAN/TI-2 using an action-research (AR), which results in practical and academic contributions. The practical one was the BPO deployment and alignment of business strategy, process, people and IT. The academic was the evaluation of Ciborra's criticism to this context.

The next section provides a brief review of the literature about ITBSA, the MAN/TI-2 model and Ciborra's criticism. The third topic discusses the methodology under the critical theory paradigm and the research model. The fourth topic shows some of the company's characteristics, the ITBSA project, the results and, the fifth, their discussion. The last topic, presents the findings with the limitations of the research and suggestions for future research.

\section{$2 \quad$ Literature Review}

This topic brings a brief description of MAN/TI-2 and four Ciborra's criticism about ITBSA.

\subsection{MAN/TI-2 Model}

According to Carvalho, Laurindo [5], the models that address the IT role in organizations can be classified into four groups: diagnostic, prescriptive, focused on actions, and integrative, which are those that add various elements of previous approaches. Laurindo [6] proposed the MAN/TI-2, an integrative model with two focus groups. The group of a company's structural factors and IT organizational factors. Table 1 represents the group of company's structural factors applied to this research. 
Table 1. MAN/TI-2 structural factors (adapted from Laurindo [2])

\begin{tabular}{|l|l|l|}
\hline $\begin{array}{l}\text { Company's structural } \\
\text { factors }\end{array}$ & \multicolumn{1}{|c|}{ Analysis Models } & \multicolumn{1}{c|}{ Author } \\
\hline $\begin{array}{l}\text { Business Strategy } \\
\text { decomposition } \\
\text { in information needs }\end{array}$ & $\begin{array}{l}\text { a) Competitive forces } \\
\text { b) Generic competitive strategies } \\
\text { c) SWOT analysis } \\
\text { d) Critical Success Factors } \\
\text { à Prioritized applications }\end{array}$ & $\begin{array}{l}\text { Porter (1979) } \\
\text { Porter (1996) } \\
\text { Porter (1979) } \\
\text { Rockart (1979) } \\
\text { Torres (1989) }\end{array}$ \\
\hline $\begin{array}{l}\text { Actual and Potential } \\
\text { role of IT in the company }\end{array}$ & $\begin{array}{l}\text { a) Strategic GRID } \\
\text { b) Information Intensity Matrix }\end{array}$ & $\begin{array}{l}\text { Nolan, MacFarlan (2005) } \\
\text { Porter, Millar (1985) }\end{array}$ \\
\hline $\begin{array}{l}\text { ITBSA perspective } \\
\text { adopted }\end{array}$ & a) Strategic alignment model & $\begin{array}{l}\text { Henderson \& } \\
\text { Venkatraman (1993) }\end{array}$ \\
\hline Network enterprise & $\begin{array}{l}\text { a) Evaluation of actual and } \\
\text { potential role of internet in the } \\
\text { company (evolutionary, }\end{array}$ & $\begin{array}{l}\text { Porter (2001) } \\
\text { Tappiscot (2001) } \\
\text { Amitt, Zoot (2001) } \\
\text { Anghern (1997) }\end{array}$ \\
\hline
\end{tabular}

\subsection{Four Ciborra's Criticisms about ITBSA}

Ciborra [3] disassembles the concept of ITBSA revisiting the history of publications criticizing the approach of Henderson and Venkatraman's model [7], highlighting the collapse of research programs and incentives to the subject sponsored by large firms. Four of the main Ciborra's criticisms follow below:

C1: The most careful consideration has been obtained from field observations and not from models, pointing out that strategic practices for alignment, such as "hospitality", "care", "culture" make more sense for management, suggesting that the human and social factors cannot be disregarded in this analysis;

C2: The strategic alignment process requires experimentation and is not observed or measured. Many information systems that supported the competitiveness emerged from this process and not from a structured approach. Phenomena, such as unexpected surprises, demand opportunities; adjustments arise from the field forcing managers to improvise. Ciborra [8] defined bricolage as adjustments by combining the resources available. "Let the world help you". Stahl [9] features that Ciborra was inspired by the notion of Weick [10] on improvisation and bricolage. The author of bricolage is someone who orders the chaos, using the local context and resources that have available;

C3: The graphical representation of abstracted alignment patterns can raise managers' awareness to align, but this is not enough to promote alignment in practice. The most detailed model of the concept remains confined in a world of idealized abstractions, with little impact on practice, considering them empty;

C4: Ciborra [4] discusses whether it is possible to achieve the goals promised by strategic planning processes, obtaining sustainable competitive advantages. He suggests that IT planning must be less formal, with greater freedom of experimentation and learning posture to take advantage of opportunities, besides being directed to innovation. 
According to Stahl [9], Ciborra's works contributed to criticizing the heroic view of research on management and on IT, casting doubt on the objectivity of scientific statements derived from the natural sciences, which are useful in these areas.

\section{Methodology}

This section shows the action-research method under critical theory paradigm adopted, and the research model, with the propositions to be validated.

\subsection{Action-Research (AR)}

According to Thiollent [11], AR is a type of social research with an empirical basis designed and built in close association with an action or resolution of a problem in which the researcher and the participant's representative of the situation are involved collaboratively. AR goals may be defined with a practical goal and an academic goal. The practical one aims to contribute to the best possible solution to the problem centrally considered. The academic goal aims to obtain information that would be difficult to reach using other procedures, in order to increase the knowledge base of certain situations. For Coughlan and Brannick [12], AR is appropriate when the research question relates to describing the unfolding of a series of actions over time in a given group, to explain how and why the action of a member can change some aspects of the system. In this context, AR was the adequate approach for this research, once the ITBSA was required by the company and this project was an opportunity to observe the Ciborra's criticism. This research falls into the category of the critical theory paradigm. According to Coghlan and Coughlan [13], the ontological point of view of this theory, reality is considered "virtual", formed by social, economic, ethnic, political, cultural and gender; it is influenced by those trying to observable over there, and, from the epistemological point of view, the findings are mediated by these values. In this category, the researcher assumes the role of "transformative intellectual" amending the social world in which the participants live.

\subsection{Research Model}

This AR followed the three-stage route proposed by Coghlan and Coughlan [13]. First, the research context and purpose were established, defined by the adoption of Ciborra criticisms about ITBSA: C1), C2), C3) and C4) as four research proposition. Second, the main stage, performed in more than one cycle, consists of six steps: data collection, data feedback to participants, analysis, action planning, implementation, and evaluation. This stage was applied to each model of MAN/TI-2, with up to two cycles for the same model, promoting the technical results for the company. The last stage, monitoring, required the researcher's reflection over all the main stages and it was performed through active proposition observation. Figure 1 shows the Research Model. 


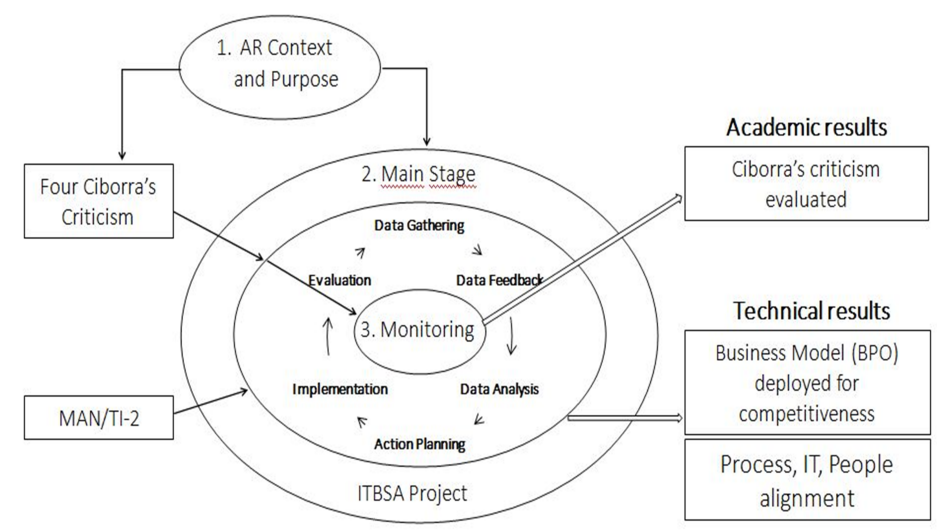

Fig. 1. ITBSA Project and AR (adapted from Coghlan and Coughlan [13])

\section{Results}

\subsection{The Company and its IT Environment}

The company, at which this research was carried out, is a small developer and construction firm founded in 2007 with approximately fifty internal and external employees, PBPQ-level A certification (Brazilian Program for Productivity and Housing Quality) and ISO 9001 certified. The main products are incorporation, construction and sales of units in popular standard condominiums for the "Programa Minha Casa Minha Vida", a Brazilian government program, in five cities in Brazil. It has a strategic business unit, the traditional development and construction of its own works and services sold to real estate partners, which was used as an initial motivation to BPO modeling. Most business processes are operated centrally and are supported by an ERP system (Enterprise Resource Planning) specific to real estate industry. This ERP supports the parameterization of several companies separately, allowing remote access by users. IT is centralized with remote accesses by some areas, such as external sales offices and buildings operations.

\subsection{The ITBSA Project and Practical Results}

This AR was conducted by an ITBSA project sponsored by the board and led by the researcher. The ITBSA was facilitated by the company's culture and compromise with quality management and desire to improve its IT maturity. The two most important practical results successfully reached were the BPO deployed as a strategic business unit, focused on revenue generation. It was defined as a set of business process offerings, such as supplies, financials, quality management, sales operations, bank collection, customer relationship management and IT solutions as a service for qualified real estate partners. The second 
was the alignment of business processes, promoting reduction of departmental barriers, requiring involvement from people and effective support from IT. This project also has built and disseminated the company view regarding its competitive strategy, IT position on this view, as well as has influenced the attitudes of the participants regarding strategic agenda. The project team involved the board of directors, engineering team, architect, supply and finance supervisors and others.

\subsection{Academic Results}

The results show a partial confirmation of proposition $\mathrm{C} 1$ and $\mathrm{C} 2$ and full confirmation of C3 and C4. The table 2 represents a sample of data gathered during the mais stage of ITBSA project and monitoring stage.

Table 2. Sample of observation registered during the AR

\begin{tabular}{|c|c|c|}
\hline Model & $\begin{array}{c}\text { Main Stage: } \\
\text { MAN/TI-2 deliverables } \\
\text { AR cycles }\end{array}$ & $\begin{array}{l}\text { Monitoring: } \\
\text { Research } \\
\text { reflection }\end{array}$ \\
\hline \begin{tabular}{|c|} 
SWOT \\
Analysis
\end{tabular} & $\begin{array}{l}\text { Cycle 1: } \\
\text { Data collection: Five SWOT interviews; } \\
\text { Data feedback: SWOT statements confirmed; } \\
\text { Data analysis: SWOT consolidation and review; } \\
\text { Action planning: Planned meetings to discuss } \\
\text { SWOT with four areas; } \\
\text { Implementation: SWOT discussed with four } \\
\text { areas and inputs for the company's IT strategy; } \\
\text { Evaluation: Team awareness of the strategic } \\
\text { agenda and of the importance of IT. }\end{array}$ & $\begin{array}{l}\text { This analysis results in a } \\
\text { partial confirmation of } \\
\text { C1 and in an annotation } \\
\text { of the research limitations. }\end{array}$ \\
\hline
\end{tabular}

The strategic grid tool used brings a discussion of the actual and future views about IT. It conducts to some observation about the strategic alignment process like it was noticed by the management team; It was not "measured"; it was stimulated by a structured approach (grid framework) and also by improvisation posture, supporting partial confirmation of $\mathrm{C} 2$. On the other hand, the strategic alignment model, with a graphical representation of abstracted alignment patterns, have helped manager's awareness to align some business objectives and IT portfolio, but this model alone was not enough to promote alignment in practice, supporting confirmation of C3.

\section{Results Discussion}

During the monitoring stage, the ITBSA project was observed to have stimulated the participants' reflections on competitiveness, on the role of IT, which had not 
been made earlier; promoted changes, and learning influenced by some strategic guidelines. Some considerations about each proposition are presented as follows:

C1: Partially confirmed. More attentive reflection on alignment was obtained from the field and not just from models. However, this research was limited, requiring a closer examination of the importance of strategic practices, such as "care", "hospitality" and "cultivation". We suggest covering this gap in future research;

C2: Partially confirmed. The BPO analysis and the identification of new potential opportunities for providing services to partners highlight the recognition that a business strategy can also arise from emerging and bricolage settings by combining the available resources towards innovation. However, is there no full agreement about Ciborra's consideration that the competitiveness agenda comes only from the "bricolage" process, and not from a "structured approach". This work confirmed that MAN/TI-2, a structured model in essence, also promoted and guided the strategic discussion. Due to its own limitation, the research could not provide any evidence of the $\mathrm{C} 2$ statement regarding the impossibility to measure the strategic alignment, which we suggest considering in a future research;

C3: Confirmed. It was showed that the gap of promoting alignment in practice came not from MAN/TI-2 models but was stimulated by the research approach based on the paradigm adopted and actions executed during the AR main stage;

C4: Confirmed. The actions proposed during the main stage cycles, influenced by the author and participants, gave freedom to experiment, promoting adequate plasticity, leading to a real business modeling driven by the competitive environment, learning along the way and actions, as suggested by Ciborra.

\section{Conclusion}

The purpose of the research was to assess four Ciborra's criticism for ITBSA in a company of the Real Estate sector. It was considered partially satisfactory, given its limitation, to confirm the complete statements of two out of four propositions, but was considered satisfactory regarding the practical contribution to the company studied.

The MAN/TI-2 models promoted the collection of input for strategic business planning and IT using a structured approach. Research on the paradigm of critical theory held by the ITBSA project stimulated the researcher and participants to plan, execute and analyze actions, encouraging the bricolage process, cyclic learning, which according to Ciborra, are key elements for innovation to achieve sustainable competitive advantage aligned with the needs in the field. Then, a combination of an ITBSA model under an action-research positively contributed to new business modeling and knowledge generation.

In order to address the research limitations to validate the uncovered statements from the propositions studied, we recommend a more comprehensive literature review about the constructs such as "hospitality", "care", "culture" and its sense for management as future research, considering how human and social factors could be included in this analysis. Future research should also discuss 
the strategic alignment measurement issue and, finally, explore ontological and epistemological issues that underlie the different views on the debate related to rationality in the literature on information systems, as studied by Ciborra.

\section{References}

1. Camargo, C., Monetti, E., Alencar, C., Moraes, R.: A Inteligência Competitiva como Ferramenta de Apoio à Decisão em Empresas de Médio Porte: Estudo de Caso no Setor do Real Estate. In: 14th Conferência Internacional da LARES. Rio de Janeiro (2014)

2. Laurindo, F.: Tecnologia da Informação: Planejamento e Gestão de Estratégias. Atlas, São Paulo (2008)

3. Ciborra, C.: De Profundis? Deconstructing the Concept of Strategic Alignment. Scandinavian Journal of Information Systems 9(2), 57-82 (1997)

4. Ciborra, C.: Digital Technologies and the Duality of Risk. Centre for Analysis of Risk and Regulation, London School of Economics and Political Science, London (2004)

5. Carvalho, M., Laurindo, F.: Estratégia Competitiva: Dos Conceitos à Implementação. Atlas, São Paulo (1997)

6. Laurindo, F.: Tecnologia da Informação como Suporte às Estratégias Empresariais. Redes entre Organizações Eficácia nas Organizações, Atlas, São Paulo (2005)

7. Henderson, J.C., Venkatraman, H.: Strategic alignment: Leveraging information technology for transforming organizations. IBM systems journal 32(1), 472-484 (1993)

8. Ciborra, C.: The labyrinths of information: Challenging the wisdom of systems: Challenging the Wisdom of Systems. Oxford University Press (2002)

9. Stahl, B.C.: The Obituary as Bricolage: The Mann Gulch Disaster and the Problem of Heroic Rationality. European Journal of Information Systems 14(5), 487-491 (2005)

10. Weick, K.E.: The Collapse of Sensemaking in Organizations: The Mann Gulch Disaster. Administrative science quarterly pp. 628-652 (1993)

11. Thiollent, M.: Metodologia da Pesquisa-ação. In: Metodologia da pesquisa-ação. Cortez (2011)

12. Coghlan, D., Brannick, T.: Doing Action Research in your Own Organization. Sage (2008)

13. Coughlan, P., Coghlan, D.: Action Research for Operations Management. International journal of operations \& production management 22(2), 220-240 (2002) 